the lion runs to his prey with his nose to the ground, and the action of the bloodhound is valuable on account of his fine scent. It seems with mind as mere knower and nonmanipulator of action these performances could not be put through.

144 Well Street, Hackney, May 26.

A. Bowman.

\section{Musical Sands.}

MAY I record the discovery of musical sands at places along the shore between Ramsgate and Kingsgate. The sand occurs in small patches close to the chalk cliffs, the largest patch being found at Joss Gap. In composition the sand is very similar to that of Studland Bay, but the individual grains are more polished, and the proportion of denser minerals far higher. Of course, the sand can only be experimented upon when it has been uncovered by the sea for a sufficient length of time to enable it to become dry, and it gives remarkable results when tested in the ordinary way-especially when placed in a china vessel and struck with a wooden plunger.

June 8. Cecil Carus-Wilson.

\section{THE STUDY OF BACTERIAL TOXINS.}

$7 \mathrm{HE}$ study of the toxins produced by bacteria is one of the most important branches of bacteriological research. The solution of some of the main problems of immunity and disease depends upon the knowledge that can be gained with reterence to the nature of the bacterial toxins and their mode of action upon the animal body.

The methods introduced by Pasteur, Koch, and other observers have rendered it possible to detect and to isolate the specific agents in a number of infective processes. The number of infective diseases that have been definitely associated with the action of bacteria is considerable, e.g. tuberculosis, cholera, diphtheria, typhoid fever, \&c.

It was natural that the earliest attempts to prevent the invasion of the animal body by these microparasites should be based more or less on the principles of Jennerian vaccination. An attenuated virus, for example, was taken and used directly as a vaccine in order to produce, if possible, an active immunity to the disease in question. This system of protective inoculation was tested in a number of diseases, and notably in infective diseases of the lower animals. The anthrax vaccine employed for the protection of cattle and sheep is a typical example of such immunising methods, whilst in recent years analogous methods of protective inoculation have been extensively used in certain diseases of man.

The study of the microparasites associated with diphtheria and tetanus showed that organisms of this type possessed not merely infective but likewise marked toxic properties. It was further established that these toxic properties were the determining factors in the production of the graver symptoms in cases of diphtheria and tetanus. It therefore became apparent that in diseases of this order, the point of cardinal importance was to combat, if possible, the toxins produced in their course. The laboratory experiments made with the diphtheria and tetanus organisms demonstrated that the poisons were soluble products of the bacterial cells in question, and were excreted into the nutrient fluids in which they had been cultivated. These toxins were proved to be of a specific nature, as they reproduced the essential general symptoms of the diseases.

Diphtheria and tetanus are therefore intoxications of the body, due to the action of specific soluble poisons produced by the parasites at the seat of infection. The toxins, on being introduced into suitable animals in carefully regulated doses, produced an active immunisation of the animals characterised by the formation in their blood of anti-bodies as regards the toxins in question-in other words, antitoxins resulted. The antitoxic serum, when added to the toxin in vitro, robbed the toxin of its poisonous properties, and, probably in virtue of some chemical combination between toxin and antitoxin, a neutral mixture resulted. The serum containing these specific anti-bodies, on introduction into other animals, conferred on them a passive immunity. They were protected against the action of the toxin in question, and, most important of all, the serum was efticacious in the case of an already existing intoxication-it possessed curative as well as protective properties. If a large animal, such as a horse, was actively immunised by injection of the soluble toxins, considerable quantities of these antitoxic substances were formed and accumulated in its blood and bloodserum. In this way the serum of an animal highly charged with antitoxins became a valuable and innocuous vehicle for the introduction of these preventive and curative substances into the human system. The natural defensive forces of the body were thereby reinforced, and in the right direction. This method of serum therapeutics has had brilliant results in the case of diphtheria, and has been demonstrated to be a feasible therapeutic method in the case of tetanus. These maladies belong to the group of intoxicative diseases. There remained, on the other hand, a large number of diseases in which a general multiplication of the microorganisms in their host appeared to be the salient feature. It has been usual to call these, in contradistinction to the former, infective diseases. The successful results in the case of diphtheria led to the extensive study on similar lines of infective organisms generally. A systematic search was made for soluble bacterial poisons, as their detection would be likely to lead to valuable additions to antitoxic serum therapeutics.

The researches in this direction met with unexpected difficulties and disappointments. The results obtained in the case of diphtheria and tetanus were not found to be of general application. Each organism had therefore to be taken on its own merits, and individually studied. It speedily became apparent that, as regards a considerable number of infective agents, the conditions were not the same. On cultivation in fluid media no distinct evidence of the production of soluble poisons could be obtained, or, if present, they were so in an inappreciable amount. The attempts, therefore, to produce antitoxins by the injection of such culture fluids into animals did not promise to be of much practical value. This, as a matter of fact, has proved to be the case; the various serums prepared were found to possess little or no curative value. Many infective organisms did not apparently produce their injurious effects through the agency of soluble toxins, and consequently curative methods based on the assumption resulted in failure. Research was thrown back once more upon the living infective agents, and the possibilities there might be of protecting the body directly against their invasions, or, in other words, of producing not a poison but a bacterial immunity. Bactericidal substances were found to be present in the blood of individuals who had passed through an attack of certain infective diseases, and the bactericidal action was specific as regards the infective agent in each case. For example, the blood of a patient recovering from typhoid fever is bactericidal to the typhoid organism. In the absence of soluble immunising products, there was a strong presumption that these substances were to be sought for within the bodies of the bacteria. The bacteria in that case, if injected directly into the system, would tend to produce an active immunisation of the body, and would reinforce the bactericidal properties of the tissues in specific directions. The method most generally favoured for this purpose was the in-

NO. 1755 , vOL 68] 
jection of killed cultures of the bacteria in question. The typical examples are the vaccines employed in cholera, plague, and typhoid fever for prophylactic purposes. The killed cultures of the several organisms are injected directly into the healthy individual in calculated doses, and the method is generally described as one of protective inoculation. In all these cases the innmunising value of the vaccine appears to lie essentially in the dead bodies of the bacteria it contains. The active immunisation that occurs depends upon a solution of the dead bacteria by the blood and tissues, and a consequent liberation of any immunising substances peculiar to the cells. The properties developed by the blood of the treated individuals are antibacterial and not antitoxic, or if so only to a small degree. If one assumes that the properties of the blood in such instances are purely of a bacteriolytic character, there would be no protection necessarily afforded against any poisonous substances that might be present in the bacterial cells, and liberated from them in the process of their dissolution or in the course of the disease. Whatever the point of view, the conviction is now an established one that in a number of infective diseases it is the direct study of the specific cellular agents that will be most likely to lead to results of therapeutic value. The important conclusion has been arrived at that there are two kinds of bacterial poisons-soluble toxins, which are secreted by the bacteria, and cellular toxins, which are contained within their body substance. The toxins may be either extra- or intracellular. The diphtheria and tetanus poisons, already referred to, are examples of the first group, and are to be met with in the nutrient fluids in which the organisms are cultivated. The typhoid and plague toxins are examples of the second group, and are practically absent from the culture fluids in which the specific organisms are grown. The poisonous principles are contained within the bodies of the microbes. The dead bodies of typhoid bacilli, although destitute of all infective properties, are yet toxic when introduced into animals in virtue of the intracellular toxins they contain-the animals succumb to an intoxication.

In the case of many diseases formerly regarded as purely infective in character, it has now become apparent that, in addition to the infective, the poisonous properties of the invading bacterial cells have to be taken into account. Any therapeutic endeavours of a curative character, it appears to the writer, ought therefore to be based on the presumption that every infection implies, sooner or later, an intoxication.

The number of infective organisms in connection with which research has failed to demonstrate soluble toxins of possible clinical importance is considerable. The presumption in such cases is that the missing toxins are intracellular, and that if antitoxic principles of treatment are to be devised they must be based on a knowledge of the nature and properteis of these cellular poisons. A vital question consequently for bacteriologists at the present moment is the relation of intracellular toxins to immunity. The study of the intracellular constituents of bacteria has, it will be obvious, assumed great importance on account of the issues involved. It is interesting to note, by way of parenthesis, how generally biological research is being attracted to the direct study of the cell, and how widely it is being recognised that the processes of life, whether of a natural or a morbid character, are in their essentials of an intracellular nature. In this respect the researches of Buchner were of wide biological significance. They were suggestive of much more than a theory of a cell-free alcoholic fermentation of sugars. And in the bacteriological field the original investigations of Koch, and the preparation by him of tuberculin from the tubercle bacillus, drew general attention to the important results that might be obtained from the study of the bacterial cell and its constituents. Various methods are employed with this object in view. The killed cultures of bacteria may be used, and their physiological effects determined by injection into animals, or by chemical means extracts may be prepared from the organisms and their effects similarly tested, or mechanical methods may be adopted in order to obtain the fresh intracellular juices.

In the investigations carried out by the writer, in conjunction with Mr. Rowland, during the past four years, mechanical methods were selected as the best adapted for the general purpose in view, viz. the study of the intracellular toxins and ferments of bacteria and other cells. The first essential was the elaboration of a method to obtain the plasma of such minute cells as the bacteria. The aim was to procure the fresh cell juices and to avoid their possible modification by heat or by chemical agents. For this purpose the cells were mechanically triturated by a cold grinding process. The necessary cold was most conveniently obtained by the use of liquid air. It was found that the cells could be mechanically broken up when in the brittle condition produced by immersion in liquid air, without any admixture of sand or other foreign substances. A number of bacteria and other cells have been triturated in this fashion, and their fresh intracellular constituents obtained. The results in the case of the typhoid bacillus will serve to illustrate the general line of research being followed. The typhoid organisms were grown on ordinary beef broth agar, and after careful washing with distilled water were disintegrated in a mechanical contrivance at the temperature of liquid air $\left(-180^{\circ}\right.$ C.). The disintegrated mass was freed from insoluble suspended particles by centrifugalisation, and an opalescent fluid, representing the celljuices of the organism, resulted. The typhoid celljuices obtained by this method, on inoculation into animals in small doses, invariably proved toxic or fatal. It was therefore concluded that the typhoid bacillus contains within itself an intracellular toxin and that $i l$ is possible to extract it from the organism.

The typhoid cell-juices were further tested for immunising and other properties, and were administered subcutaneously to suitable animals. The experiments showed that the serum of the monkey, after injection of the typhoid cell-juices, possessed antibacterial and antitoxic properties, inasmuch as the serum protected experimental animals against the typhoid bacilli, and also against the intracellular toxin obtained from them. The serum was found to possess curative and preventive properties as regards the typhoid bacillus and the intracellular toxin extracted from the same organism. The research thus afforded proof that in the case of one species of pathogenic bacterium, the intracellular juices of the organism, when injected into a suitable animal, give rise to the production of a serum which is both bactericidal to the organism itself and antitoxic as regards a toxin contained in its substance.

The results already obtained are such as to encourage further inquiry as to the possibility of their practical application in the case of typhoid fever, as well as to determine in how far such properties of the cell-juice are shared by other pathogenic microbes. The particular method employed has proved of value in the study of a distinct class of toxins and ferments brought to light by recent research which are contained and operate within the cell and bacterium, in contradistinction to the well-known class of toxins which are extracellular, i.e. extruded during life from the cell to the surrounding medium. The importance attached to the intracellular group of bacterial poisons is evidenced by the increasing attention that is now being paid to their study.
Allan Macfad yen.

NO. I 755, VOL. 68] 